\title{
Endocytosis: Past, Present, and Future
}

\author{
Sandra L. Schmid ${ }^{1}$, Alexander Sorkin ${ }^{2}$, and Marino Zerial ${ }^{3}$ \\ ${ }^{1}$ Department of Cell Biology, UT Southwestern Medical Center, Dallas, Texas 75390 \\ ${ }^{2}$ Department of Cell Biology, University of Pittsburgh School of Medicine, Pittsburgh, Pennsylvania 15261 \\ ${ }^{3}$ Max Planck Institute of Molecular Cell Biology and Genetics, 01307 Dresden, Germany \\ Correspondence: sandra.schmid@utsouthwestern.edu
}

Endocytosis, the process of cellular ingestion, $E_{\text {may have been the driving force behind evo- }}$ lution of the eucaryotic cell (de Duve 2007). Acquiring the ability to internalize macromolecules and digest them intracellularly would have allowed primordial cells to move out from their food sources and pursue a predatory existence; one that might have led to the development of endosymbiotic relationships with mitochondria and plastids. Thus, it is fitting that endocytosis was first discovered and named as the processes of cell "eating" and "drinking." In 1883, the developmental biologist Ilya Metchnikoff coined the term phagocytosis, from the Greek "phagos" (to eat) and "cyte" (cell), after observing motile cells in transparent starfish larva surround and engulf small splinters that he had inserted (Tauber 2003). Decades later, in 1931, Warren H. Lewis, one of the earliest cell "cinematographers" coined the term pinocytosis, from the Greek "pinean" (to drink), after observing the uptake of surrounding media into large vesicles in cultured macrophages, sarcoma cells, and fibroblasts by time-lapse imaging (Lewis 1931; Corner 1967).

Importantly, these pioneering studies also revealed that the function of endocytosis goes well beyond eating and drinking. Indeed, Metchnikoff, considered one of the founders of modern immunology, realized that the phagocytic behavior of the mesodermal amoeboid cells he had observed under the microscope could serve as a general defense system against invasive parasites, in the larva as in man. This revolutionary concept, termed the phagocytic theory, earned Metchnikoff the 1908 Nobel Prize in Physiology or Medicine for his work on phagocytic immunity, which he shared with Paul Ehrlich who discovered the complementary mechanisms of humoral immunity that led to the identification of antibodies (Vaughan 1965; Tauber 2003; Schmalstieg and Goldman 2008). The phagocytic theory was a milestone in immunology and cell biology, and formally gave birth to the field of endocytosis.

Key discoveries over the intervening years, aided in large part by the advent of electron microscopy, revealed multiple pathways for endocytosis in mammalian cells that fulfill multiple critical cellular functions (Fig. 1). These mechanistically and morphologically distinct pathways, and their discoverers, include clathrin-mediated endocytosis (Roth and Porter 1964), caveolae uptake (Palade 1953; Yamada 1955), cholesterol-sensitive clathrin- and caveolae-independent pathways (Moya et al. 1985; Hansen et al. 1991; Lamaze et al. 2001), and, more recently, the large capacity CLIC/GEEC pathway (Kirkham et al. 2005). In place of Metchnikoff's splinters, many of these discoveries resulted

Editors: Sandra L. Schmid, Alexander Sorkin, and Marino Zerial

Additional Perspectives on Endocytosis available at www.cshperspectives.org

Copyright (C) 2014 Cold Spring Harbor Laboratory Press; all rights reserved; doi: 10.1101/cshperspect.a022509

Cite this article as Cold Spring Harb Perspect Biol 2014;6:a022509 
S.L. Schmid et al.
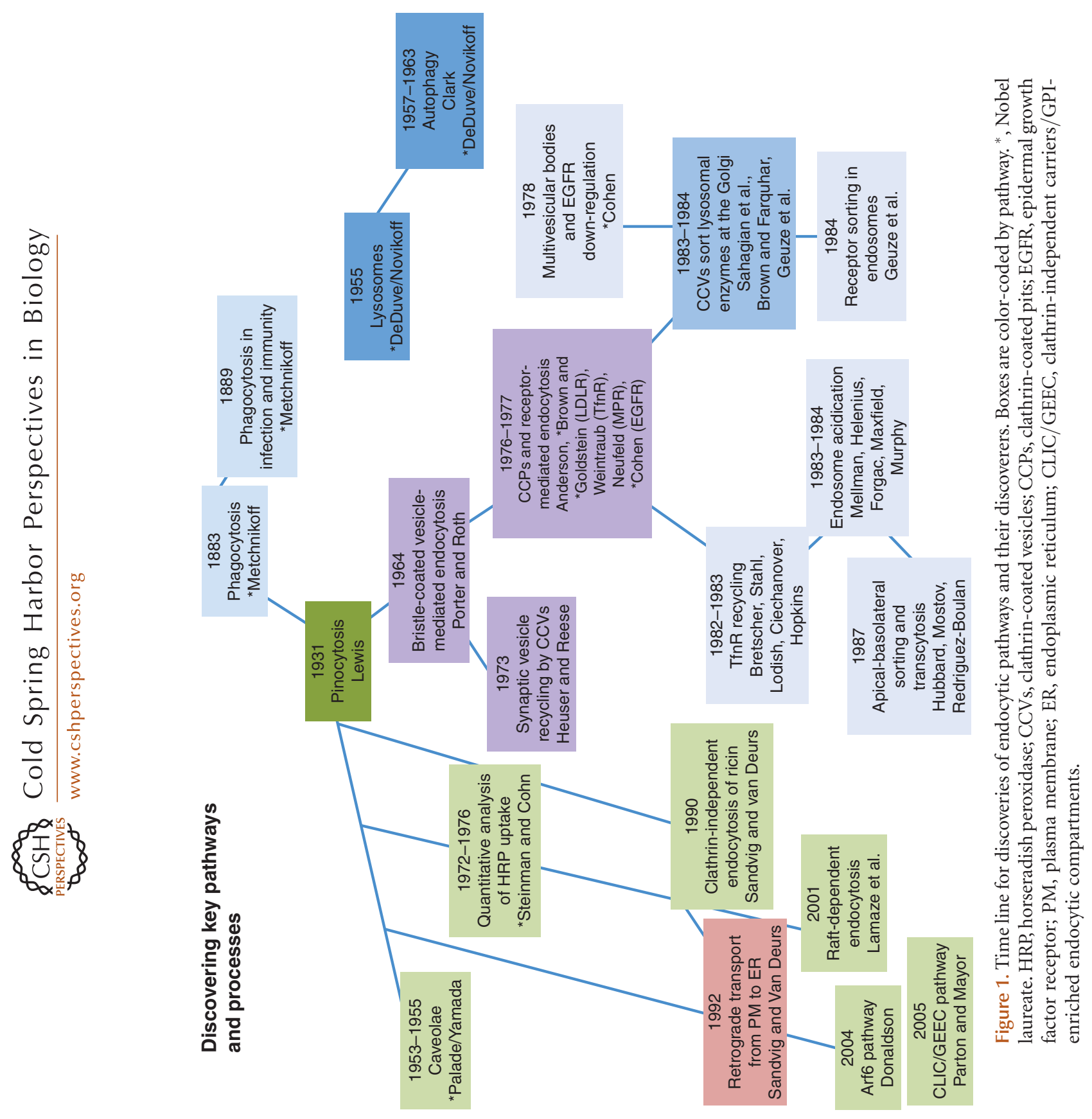
from the detection and tracking of internalized HRP-, ferritin-, or gold-conjugated ligands by electron microscopy. These electron-dense tracers allowed researchers to identify cellular structures associated with the uptake and intracellular sorting of receptor-bound ligands. A particularly striking example is the pioneering work of Roth and Porter, who in 1964 observed the uptake of yolk proteins into mosquito oocytes. To synchronize uptake, they killed female mosquitos at timed intervals after a blood feed and observed the sequential appearance of electrondense yolk granules in coated pits, coated and uncoated vesicles, and progressively larger vesicles. Their remarkable observations accurately described coated vesicle budding, uncoating, homo- and heterotypic fusion events, as well as the emergence of tubules from early endosomes (Fig. 2), all of which are now known hallmarks of the early endocytic trafficking events.

Another milestone in the field of endocytosis was the discovery of the lysosome by Chris- tian de Duve (Appelmans et al. 1955). Whereas the finding of phagocytosis and other endocytic pathways was possible through microscopy, the discovery of lysosomes originated from a biochemical approach (Courtoy 2007), which benefited from the invention of the ultracentrifuge. de Duve and coworkers observed that preparations of acid phosphatase obtained by subcellular fractionation had an unusual behavior: contrary to most enzymatic activities, the activity of acid phosphatase increased rather than decreased with time, freezing-thawing of the fractions and the presence of detergents. Interestingly, the same was true for other hydrolases, which depended on acidic $\mathrm{pH}$ for their optimal activity. This led him to postulate that the acid hydrolases were contained in acidified membrane-bound vesicles. In collaboration with Alex Novikoff, he visualized these vesicles, the lysosomes, by electron microscopy (Beaufay et al. 1956) and later showed their content of acid phosphatase (Farquhar et al. 1972). In

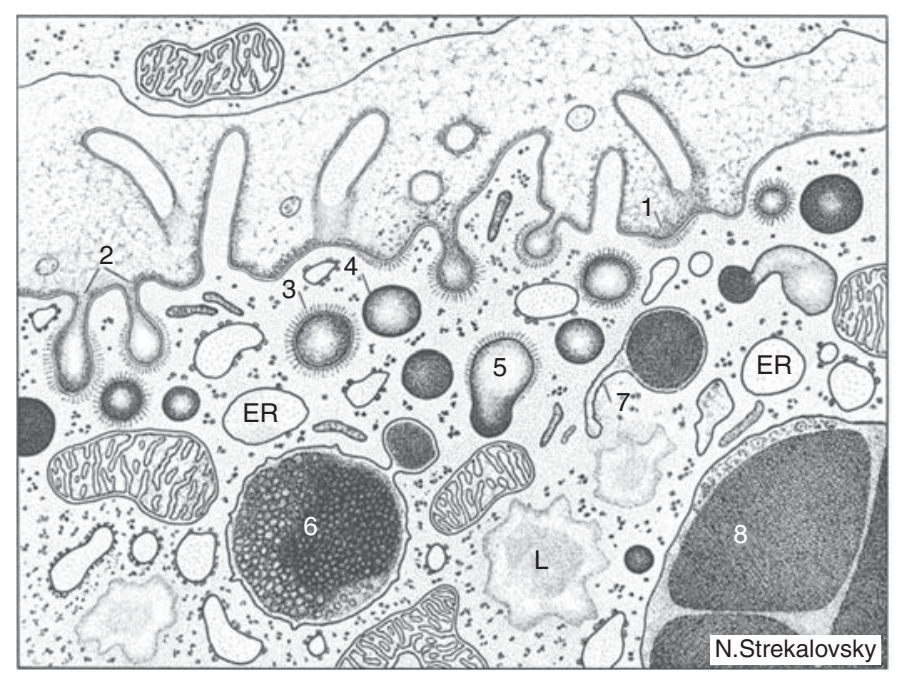

Figure 2. Fiftieth anniversary of the discovery of clathrin-mediated endocytosis by Roth and Porter (1964). The image is the hand-drawn summary of observations made by electron microscopic examination of the trafficking of yolk proteins in a mosquito oocyte. Note the many details, later confirmed and mechanistically studied over the intervening 50 years. These include the growth, invagination, and pinching off of coated pits $(1,2)$, which concentrate cargo taken up by coated vesicles (3), the rapid uncoating of nascent-coated vesicles (4), homotypic fusion of nascent endocytic vesicles in the cell periphery (5), the formation of tubules from early endosomes (7), and changes in the intraluminal properties of larger endosomes (6). Finally, yolk proteins are stored in granules as crystalline bodies (8). (From Roth and Porter 1964; reprinted, with express permission, from Rockefeller University Press (C) 1964, The Journal of Cell Biology 20: 313-332, doi: 10.1083/jcb.20.2.313.) 
1974, de Duve was awarded the Nobel Prize for Physiology or Medicine for his seminal finding of the lysosomes and peroxisomes. He shared it with Albert Claude and George E. Palade "for their discoveries concerning the structural and functional organization of the cell." The importance of this work lies also in the significant therapeutic applications that followed. The discovery by Elizabeth Neufeld and collaborators of uptake of lysosomal enzymes by cells provided the foundation for enzyme replacement therapy for lysosomal storage disorders (Neufeld 2011).

In the 1970s, research in endocytosis entered the molecular era. Using de Duve and Albert Claude-like methods of subcellular fractionation, Barbara M. Pearse purified clathrincoated vesicles from pig brain (Pearse 1975). A year later, she isolated a major protein species of $180 \mathrm{kDa}$, which she named clathrin "to indicate the lattice-like structures which it forms" (Pearse 1976). It was a breakthrough that inaugurated the molecular dissection of clathrinmediated endocytosis.

Over the intervening years, the continued application of microscopy (which now spans from electron cryotomography to live cell, high-resolution fluorescence microscopy), genetics (in particular, in yeast, Caenorhabditis elegans and Drosophila melanogaster), biochemistry (including cell-free reconstitution of endocytic membrane trafficking events), as well as molecular and structural biology have revealed a great deal about the cellular machineries and mechanisms that govern trafficking along the endocytic pathway. A partial, and because of space limitations, necessarily incomplete list of milestones (Table 1) shows how new technologies (e.g., green fluorescent protein [GFP] fusion proteins, total internal reflection microscopy, siRNA knockdowns) enable new discoveries.

\section{OVERVIEW OF ARTICLES}

In organizing this collection, our intention was to summarize a great deal of established concepts and mechanisms, and also to highlight outstanding questions and controversies in the field. We first describe our current knowledge of the core molecular machinery governing endocytosis and transport along the endocytic pathway, followed by examples of the importance of endocytic trafficking in organismal physiology and development, and how defects in endocytosis or its cooptation can lead to and also benefit human disease. Each article ends with a discussion of future perspectives, including outstanding questions, challenges, and opportunities for new discovery.

The order of articles reflects broadly the spatiotemporal progression of cargo from the plasma membrane toward the lysosome. We begin with several articles that describe our current understanding of the molecular machinery and mechanisms driving entry of cargo (e.g., receptors and bound ligands) into the cell, by clathrin-dependent and -independent endocytosis (Traub and Bonifacino 2013; Kirchhausen et al. 2014; Mayor et al. 2014; Merrifield and Kaksonen 2014; Mettlen and Danuser 2014). Following internalization, the endocytosed material is shuttled along an ultrastructurally complex and dynamic pathway of tubular and vesicular compartments collectively known as endosomes, and described in the article by Klumperman and Raposo (2014), from which they can be sorted for recycling back to the cell surface or delivered to lysosomes for degradation. Several articles are then devoted to the signals and mechanisms governing these sorting decisions. They cover the molecular machineries responsible for the compartmental organization and function of endosomes (WandingerNess and Zerial 2014) and sorting and transport along endolysosomal pathways (Bissig and Gruenberg 2013; Henne et al. 2013; Burd and Cullen 2014; Piper et al. 2014). Lysosomes and lysosome-related organelles are discussed in the article by Luzio et al. 2014). Once thought to be "dead-end" receptacles responsible only for degradation, lysosomes have revealed themselves as dynamic and functionally diverse organelles that can fuse with the plasma membrane in response to extracellular cues. The common biophysical challenges faced in deforming the plasma membrane or endosomes to generate transport vesicles are discussed in 
Table 1. Some key discoveries in endocytic trafficking

\begin{tabular}{|c|c|c|}
\hline Year & Mechanistic milestones & Discoverers \\
\hline 1973 & $\begin{array}{l}\text { Identification of shibirets (dynamin) mutant in } \\
\text { Drosophila }\end{array}$ & D. Suzuki and C. Poodry \\
\hline $1974-1976$ & Zipper mechanism for phagocytosis & S. Silverstein \\
\hline $1975-1976$ & Isolation of CCVs, purification of clathrin & B. Pearse \\
\hline $1982-1984$ & Phosphomannose, M6PR, and lysosomal targeting & $\begin{array}{l}\text { W. Sly, S. Kornfeld, E. Neufeld, } \\
\text { G. Sahagian }\end{array}$ \\
\hline $1983-1984$ & $\begin{array}{l}\text { Isolation of clathrin adapters/localization to distinct } \\
\text { membranes }\end{array}$ & J. Keen, B. Pearse, M. Robinson \\
\hline 1986 & Isolation of endocytosis mutants (End) in yeast & H. Riezman \\
\hline $1986-1987$ & Isolation of vacuolar protein sorting mutants in yeast & S. Emr, T. Stevens \\
\hline 1986 & Endosome fusion in vitro & J. Gruenberg and K. Howell \\
\hline 1986 & EGF and insulin receptor signaling from endosomes & J. Bergeron and B. Posner \\
\hline 1986 & Macropinocytosis induced in stimulated cells & D. Bar-Sagi and J. Feramisco \\
\hline 1987 & Endocytic sorting motifs (FxNPxY, YxxF) & $\begin{array}{l}\text { M. Brown and J. Goldstein, } \\
\text { I. Trowbridge, T. McGraw }\end{array}$ \\
\hline $1987-1989$ & Cloning of $\mathrm{CHC}, \mathrm{CLC}, \mathrm{AP} 2$ & T. Kirchhausen, M. Robinson \\
\hline 1988 & Isolation of biochemically distinct early and late endosomes & S. Schmid and I. Mellman \\
\hline $1989-1991$ & Clathrin-mediated endocytosis reconstituted in vitro & E. Smythe, G. Warren, S. Schmid \\
\hline 1990 & Localization of endosomal Rab5 and Rab7 & P. Chavrier, R. Parton, M. Zerial \\
\hline 1991 & $\begin{array}{l}\text { Endosome to trans-Golgi network (TGN) transport } \\
\text { reconstituted in vitro }\end{array}$ & S. Pfeffer \\
\hline 1992 & Rab5 and Rab4 as early endocytic regulators in vivo & M. Zerial, R. Parton, I. Mellman \\
\hline $1992-1995$ & Caveolin/VIP21 identified as caveolar coat protein & $\begin{array}{l}\text { R. Anderson, T. Kurzchalia, } \\
\text { R. Parton, K. Simons }\end{array}$ \\
\hline 1992 & Vacuolar fusion reconstituted in vitro & W. Wickner \\
\hline $1992-1994$ & Trigger mechanism for phagocytosis of bacteria & S. Falkow, J. Galán, J. Swanson \\
\hline 1993 & Actin's role in endocytosis in yeast & H. Riezman \\
\hline 1993 & Isolation of autophagy mutants (Atg) in yeast & Y. Ohsumi \\
\hline 1993 & PI3 kinase activity (PI3P) and endosome function & S. Emr \\
\hline 1993 & Dynamin's role in clathrin-mediated endocytosis & R. Vallee, S. Schmid \\
\hline 1995 & Dynamin assembles into rings & S. Schmid, P. De Camilli \\
\hline 1996 & Clathrin-mediated endocytosis requirement for signaling & S. Schmid \\
\hline 1996 & $\begin{array}{l}\text { Long distance retrograde transport of signaling } \\
\text { endosomes in neurons }\end{array}$ & W. Mobley \\
\hline 1996 & $\begin{array}{l}\text { PI5 phosphatase activity }\left(\mathrm{PI}(4,5) \mathrm{P}_{2}\right) \text { and clathrin-mediated } \\
\text { endocytosis }\end{array}$ & P. De Camilli \\
\hline 1996 & Ubiquitin-dependent sorting in endocytosis & $\begin{array}{l}\text { R. Haguenauer-Tsapis; L. Hicke and } \\
\text { H. Riezman }\end{array}$ \\
\hline 1997 & AP3 and endosomal/lysosomal sorting & J. Bonifacino, S. Robinson \\
\hline 1998 & FYVE fingers bind to PI3P & H. Stenmark \\
\hline 1998 & LBPA in MVB biogenesis & $\begin{array}{l}\text { T. Kobayashi, R. Parton, } \\
\text { J. Gruenberg }\end{array}$ \\
\hline $1997-1998$ & Sorting nexins & G. Gill, S. Emr \\
\hline 1998 & Structural basis for Y-based sorting signal recognition & D. Owen \\
\hline 1998 & Retromer coat and endosome to TGN sorting & S. Emr \\
\hline 1998 & $\begin{array}{l}\beta \text {-Propeller structure of clathrin heavy chain terminal } \\
\text { domain }\end{array}$ & T. Kirchhausen and S. Harrison \\
\hline 1998 & Cargo-specific subpopulations of clathrin-coated pits & M. von Zastrow \\
\hline 1999 & Structure of the clathrin coat protein superhelical motifs & J. Ybe and F. Brodsky \\
\hline 1999 & Imaging green fluorescent protein-clathrin in living cells & J. Keen \\
\hline
\end{tabular}


S.L. Schmid et al.

Table 1. Continued

\begin{tabular}{|c|c|c|}
\hline Year & Mechanistic milestones & Discoverers \\
\hline 1999 & Biochemical purification of Rab5 effectors & S. Christoforidis and M. Zerial \\
\hline 1999 & Genetic screen for endocytosis mutants in C. elegans & B. Grant \\
\hline 2000 & Role of endocytosis in establishing morphogenic gradients & M. Gonzalez-Gaitan, S.M. Cohen \\
\hline 2000 & Identification of GGA coats and lysosomal sorting & $\begin{array}{l}\text { J. Bonifacino, S. Kornfeld, } \\
\text { M. Robinson }\end{array}$ \\
\hline 2000 & $\begin{array}{l}\text { Identification of endosomal sorting complex required for } \\
\text { transport (ESCRT) machinery for multivesicular body } \\
\text { (MVB) formation }\end{array}$ & S. Emr \\
\hline 2001 & Ubiquitin-dependent sorting into MVBs & R. Piper, S. Emr, H. Pelham \\
\hline 2002 & Structure of the AP2 core & D. Owen \\
\hline 2003 & Lipid conjugation of LC3/Atg8 & Y. Ohsumi \\
\hline $2003-2004$ & siRNA studies of endocytic components & $\begin{array}{l}\text { S. Robinson, E. Ungewickell, } \\
\text { A. Sorkin }\end{array}$ \\
\hline 2004 & BAR domains and membrane curvature generation & H. McMahon, P. De Camilli \\
\hline 2004 & 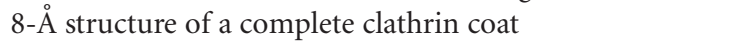 & T. Kirchhausen and S. Harrison \\
\hline 2005 & Modular design of yeast endocytosis machinery & D. Drubin and M. Kaksonen \\
\hline 2005 & $\begin{array}{l}\text { Kinome-wide RNAi analysis of clathrin-mediated } \\
\text { endocytosis (CME) and clathrin-independent } \\
\text { endocytosis (CIE) }\end{array}$ & M. Zerial and L. Pelkmans \\
\hline $2006-2008$ & Reconstitution of dynamin-mediated membrane fission & $\begin{array}{l}\text { A. Roux, P. De Camilli, S. Schmid, } \\
\text { J. Zimmerberg, V. Frolov }\end{array}$ \\
\hline 2007 & Glycosphingolipid-induced endocytosis & L. Johannes \\
\hline 2009 & $\begin{array}{l}\text { Reconstitution of Rab- and SNARE-dependent vacuolar } \\
\text { and endosome fusion from purified components }\end{array}$ & W. Wickner, M. Zerial \\
\hline 2010 & Cavins as major caveolae coat components & R. Parton; B. Nichols \\
\hline 2010 & $\begin{array}{l}\text { Reconstitution of ESCRT-dependent internal vesicle } \\
\text { formation }\end{array}$ & T. Wollert and J. Hurley \\
\hline 2012 & $\begin{array}{l}\text { Reconstitution of CCV formation from minimal } \\
\text { components }\end{array}$ & E. Ungewickell \\
\hline
\end{tabular}

the article by Johannes et al. (2014), and the endosome-specific machinery for fusion and fission that creates the dynamic network of membranes essential for protein sorting along this pathway is described by Gautreau et al. (2014). Recent work summarized by Settembre and Ballabio (2014) has provided insights into the transcriptional regulation of lysosome biogenesis, autophagy, and clearance. The article by Tooze et al. (2014) describes recent progress in autophagy or "self-eating," a cellular repair mechanism very important for cell homeostasis, defense mechanisms, and the prevention of a number of human diseases.

Not surprisingly, given its evolutionary importance, as suggested by de Duve, many of the proteins that drive endocytosis are highly conserved and can be traced to the earliest eu- karyotic ancestors; more recent additions to the endocytic machinery are likely indicative of specialization and increased regulation of the endocytic pathways during evolution (as discussed in the article by Wideman et al. 2014). Some components of the endocytic machinery play "moonlighting" functions in divergent cellular processes (see Brodsky et al. 2014). Whether these components reflect their ancestral functions and the origins of the endocytic machinery, or new vocations, remains to be determined.

The plasma membrane is the conduit for all interactions between cells and their environment. Thus, it has become clear that, besides eating and drinking, these various endocytic pathways and subsequent endosomal sorting events play critical roles in regulating multiple aspects of cell and organismal physiology. The 
Endocytosis: Past, Present, and Future

next series of articles are therefore focused on the physiological functions of endocytosis. Endocytosis controls and constantly modifies the protein composition of the plasma membrane to respond to environmental changes (i.e., upor down-regulating nutrient receptors and transporters) and is therefore essential to maintain cellular and serum homeostasis (Antonescu et al. 2014). In its specialized forms, endocytosis controls the activity and composition of neuronal synapses (Morgan et al. 2013; Cosker and Segal 2014), and immune surveillance and antigen presentation in dendritic cells (ten Broeke et al. 2013), which are critical to organismal physiology. Endocytosis of receptor tyrosine kinases and G-protein coupled receptors spatially and temporally controls their signaling activities (Di Fiore and von Zastrow 2014), whereas endocytosis of adhesion molecules and polarity markers controls cell migration and polarity. Together, these functions for endocytosis are essential for tissue morphogenesis and development (Bökel and Brand 2014; Di Fiore and von Zastrow 2014; Eaton and Martin-Belmonte 2014; Gonzalez-Gaitan and Jülicher 2014). Consequently, defects in endocytosis are linked to many human diseases (Maxfield 2014) including cancer (Mellman and Yarden 2013). Finally, many endocytic pathways are exploited by viruses, bacteria, and toxins to gain entry into the cell (Cossart and Helenius 2014), and more recently by researchers aiming to specifically and effectively deliver therapeutics for the treatment of human disease (Akinc and Battaglia 2013). Together, these articles outline the progress toward the elucidation of the molecular mechanisms of macropinocytosis and phagocytosis more than a century after Metchnikoff's pioneering microscopic observations. However, Metchnikoff used to translate his morphological observations of cells and tissues into drawings. Photomicroscopy in the 19th century was not a common method (Schmalstieg and Goldman 2008). Today, advances in light microscopy approaches allow the visualization of cells and tissues in living organisms and this practice promises a great future also in the clinics, as described by Weigert (2014) in this collection.

\section{FUTURE PERSPECTIVES}

Each article ends with a discussion of specific unanswered questions and opportunities for future research. However, collectively, we believe that the most important future challenges in endocytosis are (1) to expand our analysis beyond the current limited number of cargo molecules so as to analyze the mechanisms and physiological implications for cargo-selective regulation of endocytic trafficking; (2) to move from cell culture model systems to the study of endocytosis and endocytic trafficking in organ cultures and in vivo animal models so as to better understand the diversity of endocytic pathways and their physiological significance; and (3) to understand how endocytic trafficking and sorting processes are regulated at the cellular, tissue, and organismal levels to couple endocytosis with signaling, neurotransmission, motility, polarity, and other more complex cellular behaviors. These studies will be aided by new developments in cellular engineering, in vivo imaging, high-throughput discovery research, and computational modeling that will identify the regulatory connections that link endocytosis with other cellular processes.

\section{REFERENCES}

${ }^{*}$ Reference is also in this collection.

* Akinc A, Battaglia G. 2013. Exploiting endocytosis for nanomedicines. Cold Spring Harb Perspect Biol 5: a016980.

* Antonescu CN, McGraw TE, Klip A. 2014. Reciprocal regulation of endocytosis and metabolism. Cold Spring Harb Perspect Biol doi: 10.1101/cshperspect.a016964.

Appelmans F, Wattiaux R, de Duve C. 1955. Tissue fractionation studies. 5. The association of acid phosphatase with a special class of cytoplasmic granules in rat liver. Biochem J 59: 438-445.

Beaufay H, de Duve C, Novikoff AB. 1956. Electron microscopy of lysosome-rich fractions from rat liver. J Biophys Biochem Cytol 2: 179-184.

* Bissig C, Gruenberg J. 2013. Lipid sorting and multivesicular endosome biogenesis. Cold Spring Harb Perspect Biol 5: a016816.

* Bökel C, Brand M. 2014. Endocytosis and signaling during development. Cold Spring Harb Perspect Biol doi: 10.1101/cshperspect.a017020.

* Brodsky FM, Sosa RT, Ybe JA, O’Hallaran TJ. 2014. Unconventional functions for clathrin, ESCRTs and other endocytic regulators in the cytoskeleton, cell cycle, nucleus, and beyond: Links to human disease. 
S.L. Schmid et al.

Cold Spring Harb Perspect Biol doi: 10.1101/cshperspect.a017004.

* Burd C, Cullen PJ. 2014. Retromer: A master conductor of endosome sorting. Cold Spring Harb Perspect Biol 6: a016774.

Corner GW. 1967. Warren Harmon Lewis (1870-1964): A biographical memoir, www.nasonline.org/publications/ biographical-memoirs/memoir-pdfs/lewis-warren-h.pdf.

* Cosker KE, Segal RA. 2014. Neuronal signaling through endocytosis. Cold Spring Harb Perspect Biol 6: a020669.

* Cossart P, Helenius A. 2014. Endocytosis of viruses and bacteria. Cold Spring Harb Perspect Biol doi: 10.1101/ cshperspect.a016972.

Courtoy P. 2007. A tribute to Professor Christian de Duve on his 90th birthday. J Cell Mol Med 11: 902-905.

de Duve C. 2007. The origin of eukaryotes: A reappraisal. Nat Rev Genet 8: 395-403.

* Di Fiore PP, von Zastrow M. 2014. Endocytosis, signaling, and beyond. Cold Spring Harb Perspect Biol doi: 10.1101/ cshperspect.a016865.

* Eaton S, Martin-Belmonte F. 2014. Cargo sorting in the endocytic pathway: A key regulator of cell polarity and tissue dynamics. Cold Spring Harb Perspect Biol doi: 10.1101/cshperspect.a016899.

Farquhar MG, Bainton DF, Baggiolini M, de Duve C. 1972. Cytochemical localization of acid phosphatase activity in granule fractions from rabbit polymorphonuclear leukocytes. J Cell Biol 54: 141-156.

* Gautreau A, Oguievetskaia K, Ungermann C. 2014. Function and regulation of the endosomal fusion and fission machineries. Cold Spring Harb Perspect Biol doi: 10.1101/ cshperspect.a016832.

* Gonzalez-Gaitan M, Jülicher M. 2014. The role of endocytosis during morphogenetic signaling. Cold Spring Harb Perspect Biol doi: 10.1101/cshperspect.a016881.

Hansen SH, Sandvig K, van Deurs B. 1991. The preendosomal compartment comprises distinct coated and noncoated endocytic vesicle populations. J Cell Biol 113: 731-741.

* Henne WM, Stenmark H, Emr SD. 2013. Molecular mechanisms of the membrane sculpting ESCRT pathway. Cold Spring Harb Perspect Biol 5: a016766.

* Johannes L, Wunder C, Bassereau P. 2014. Bending "on the rocks"-A cocktail of biophysical modules to build endocytic pathways. Cold Spring Harb Perspect Biol 6: a016741.

* Kirchhausen T, Owen D, Harrison SC. 2014. Molecular structure, function and dynamics of clathrin-mediated membrane traffic. Cold Spring Harb Perspect Biol doi: 10.1101/cshperspect.a016725.

Kirkham M, Fujita A, Chadda R, Nixon SJ, Kurzchalia TV, Sharma DK, Pagano RE, Hancock JF, Mayor S, Parton RG. 2005. Ultrastructural identification of uncoated caveolin-independent early endocytic vehicles. J Cell Biol 168: $465-476$.

* Klumperman J, Raposo G. 2014. The complex ultrastructure of the endolysosomal system. Cold Spring Harb Perspect Biol doi: 10.1101/cshperspect.a016857.

Lamaze C, Dujeancourt A, Baba T, Lo CG, Benmerah A, Dautry-Varsat A. 2001. Interleukin 2 receptors and de- tergent-resistant membrane domains define a clathrinindependent endocytic pathway. Mol Cell 7: 661-671.

* Luzio JP, Hackmann Y, Dieckmann NMG, Griffiths GM. 2014. The biogenesis of lysosome-related organelles. Cold Spring Harb Perspect Biol doi: 10.1101/cshperspect.a016840.

* Maxfield FR. 2014. Role of endosomes and lysosomes in human disease. Cold Spring Harb Perspect Biol doi: 10.1101/cshperspect.a016931.

* Mayor S, Parton RG, Donaldson JG. 2014. Clathrin-independent pathways of endocytosis. Cold Spring Harb Perspect Biol doi: 10.1101/cshperspect.a016758.

* Mellman I, Yarden Y. 2013. Endocytosis and cancer. Cold Spring Harb Perspect Biol 5: a016949.

* Merrifield C, Kaksonen M. 2014. Endocytic accessory factors and regulation of clathrin-mediated endocytosis. Cold Spring Harb Perspect Biol doi: 10.1101/cshperspect.a016733.

* Mettlen M, Danuser G. 2014. Imaging and modeling the dynamics of clathrin-mediated endocytosis. Cold Spring Harb Perspect Biol doi: 10.1101/cshperspect.a017038.

* Morgan JR, Comstra HS, Cohen M, Faundez V. 2013. Presynaptic membrane retrieval and endosome biology: Defining moleculary heterogeneous synaptic vesicles. Cold Spring Harb Perspect Biol 5: a016915.

Moya M, Dautry-Varsat A, Goud B, Louvard D, Boquet P. 1985. Inhibition of coated pit formation in Hep2 cells blocks the cytotoxicity of diphtheria toxin but not that of ricin toxin. J Cell Biol 101: 548-559.

Neufeld EF. 2011. From serendipity to therapy. Annu Rev Biochem 80: 1-15.

Palade GE. 1953. Fine structure of blood capillaries. J Applied Physics 24: 1424 (Abstract from Proceedings of the Electron Microscopy Society of America).

Pearse BM. 1975. Coated vesicles from pig brain: Purification and biochemical characterization. J Mol Biol 97: 93-98.

Pearse BM. 1976. Clathrin: A unique protein associated with intracellular transfer of membrane by coated vesicles. Proc Natl Acad Sci 73: 1255-1259.

* Piper RC, Dikic I, Lukacs G. 2014. Ubiquitin-dependent sorting in endocytosis. Cold Spring Harb Perspect Biol 6: $\mathrm{a} 016808$.

Roth TF, Porter KE. 1964. Yolk protein uptake in the oocyte of the mosquito Aedes aegypti L. J Cell Biol 20: 313-332.

Schmalstieg FC Jr, Goldman AS. 2008. Ilya Ilich Metchnikoff (1845-1915) and Paul Ehrlich (1854-1915): The centennial of the 1908 Nobel Prize in Physiology or Medicine. J Med Biogr 16: 96-103.

* Settembre C, Ballabio A. 2014. Lysosomal adaptation: How the lysosome responds to external cues. Cold Spring Harb Perspect Biol doi: 10.1101/cshperspect.a016907.

Tauber AI. 2003. Metchnikoff and the phagocytosis theory. Nat Rev Mol Cell Biol 4: 897-901.

* ten Broeke T, Wubbolts R, Stoorvogel W. 2013. MHC Class II antigen presentation by dendritic cells regulated through endosomal sorting. Cold Spring Harb Perspect Biol 5: a016873.

* Tooze SA, Abada A, Elazar Z. 2014. Endocytosis and autophagy: Exploitation or cooperation? Cold Spring Harb Perspect Biol doi: 10.1101/cshperspect.a018358. 
Endocytosis: Past, Present, and Future

* Traub LM, Bonifacino JS. 2013. Cargo recognition in clathrin-mediated endocytosis. Cold Spring Harb Perspect Biol 5: a016790.

Vaughan RB. 1965. The romantic rationalist: A study of Elie Metchnikoff. Med Hist 9: 201-215.

* Wandinger-Ness A, Zerial M. 2014. Rab proteins and the compartmentalization of the endosomal system. Cold Spring Harb Perspect Biol doi: 10.1101/cshper spect.a022616.
* Weigert R. 2014. Imaging the dynamics of endocytosis in live mammalian tissues. Cold Spring Harb Perspect Biol doi: $10.1101 /$ cshperspect.a017012.

* Wideman J, Leung KF, Field MC, Dacks JB. 2014. The cell biology of the endocytic system from an evolutionary perspective. Cold Spring Harb Perspect Biol doi: 10.1101/ cshperspect.a016998.

Yamada E. 1955. J. Fine structure of the gallbladder epithelium of the mouse. Biophys Biochem Cytol 1: 445-456. 


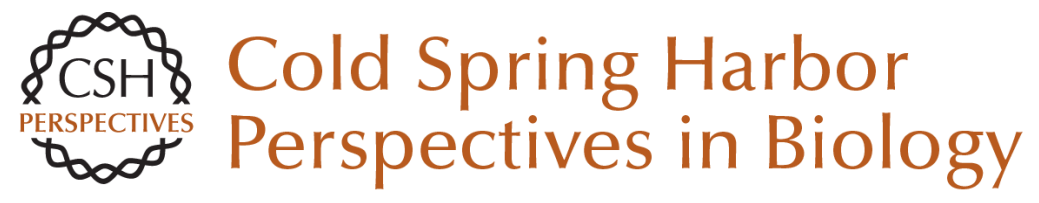

\section{Endocytosis: Past, Present, and Future}

Sandra L. Schmid, Alexander Sorkin and Marino Zerial

Cold Spring Harb Perspect Biol 2014; doi: 10.1101/cshperspect.a022509 originally published online October 30, 2014

\section{Subject Collection Endocytosis}

Endocytosis: Past, Present, and Future Sandra L. Schmid, Alexander Sorkin and Marino Zerial

Rab Proteins and the Compartmentalization of the Endosomal System Angela Wandinger-Ness and Marino Zerial

Cargo Sorting in the Endocytic Pathway: A Key Regulator of Cell Polarity and Tissue Dynamics Suzanne Eaton and Fernando Martin-Belmonte

Unconventional Functions for Clathrin, ESCRTs, and Other Endocytic Regulators in the

Cytoskeleton, Cell Cycle, Nucleus, and Beyond:

Links to Human Disease Frances M. Brodsky, R. Thomas Sosa, Joel A. Ybe, et al.

Endocytosis of Viruses and Bacteria Pascale Cossart and Ari Helenius

Lysosomal Adaptation: How the Lysosome

Responds to External Cues Carmine Settembre and Andrea Ballabio

Reciprocal Regulation of Endocytosis and Metabolism

Costin N. Antonescu, Timothy E. McGraw and Amira Klip

Endocytosis and Autophagy: Exploitation or Cooperation?

Sharon A. Tooze, Adi Abada and Zvulun Elazar
Imaging and Modeling the Dynamics of Clathrin-Mediated Endocytosis Marcel Mettlen and Gaudenz Danuser

Endocytic Accessory Factors and Regulation of Clathrin-Mediated Endocytosis Christien J. Merrifield and Marko Kaksonen

The Complex Ultrastructure of the Endolysosomal

System Judith Klumperman and Graça Raposo

The Biogenesis of Lysosomes and

Lysosome-Related Organelles J. Paul Luzio, Yvonne Hackmann, Nele M.G. Dieckmann, et al.

Endocytosis, Signaling, and Beyond Pier Paolo Di Fiore and Mark von Zastrow

Clathrin-Independent Pathways of Endocytosis Satyajit Mayor, Robert G. Parton and Julie G. Donaldson

The Role of Endocytosis during Morphogenetic Signaling Marcos Gonzalez-Gaitan and Frank Jülicher

Role of Endosomes and Lysosomes in Human Disease Frederick R. Maxfield

For additional articles in this collection, see http://cshperspectives.cshlp.org/cgi/collection/

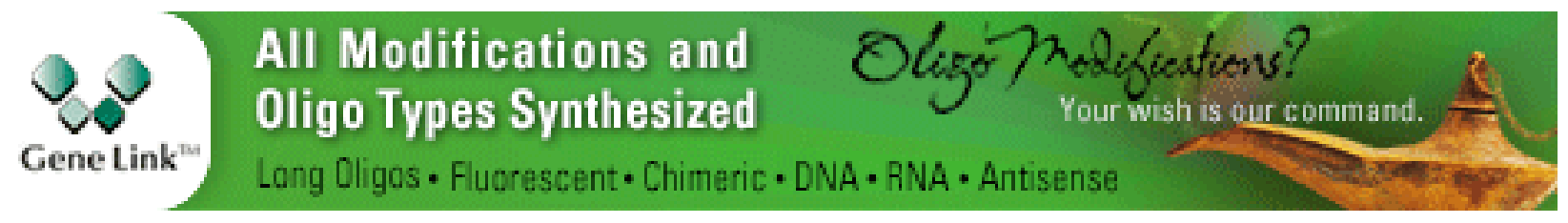


For additional articles in this collection, see http://cshperspectives.cshlp.org/cgi/collection/

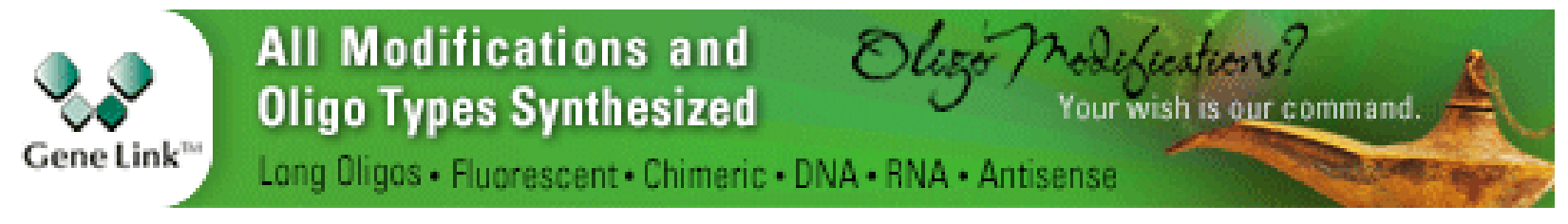

Copyright @ 2014 Cold Spring Harbor Laboratory Press; all rights reserved 